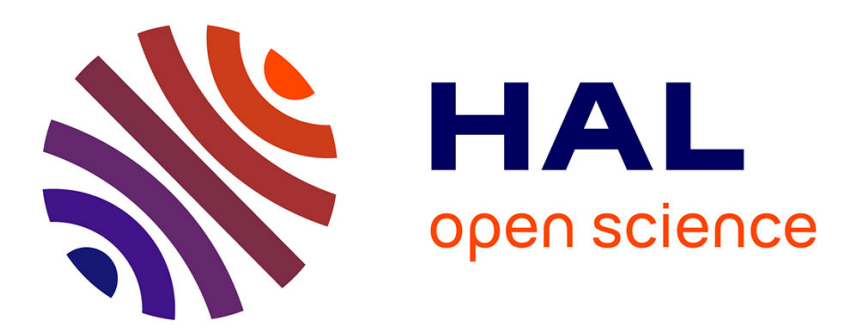

\title{
A rapid mechanism to remobilize and homogenize highly crystalline magma bodies
}

\author{
Alain Burgisser, George W. Bergantz
}

\section{To cite this version:}

Alain Burgisser, George W. Bergantz. A rapid mechanism to remobilize and homogenize highly crystalline magma bodies. Nature, 2011, 471 (10 march 2011), pp.212-216. 10.1038/nature09799 . insu-00576480

\section{HAL Id: insu-00576480 \\ https://hal-insu.archives-ouvertes.fr/insu-00576480}

Submitted on 1 Dec 2011

HAL is a multi-disciplinary open access archive for the deposit and dissemination of scientific research documents, whether they are published or not. The documents may come from teaching and research institutions in France or abroad, or from public or private research centers.
L'archive ouverte pluridisciplinaire HAL, est destinée au dépôt et à la diffusion de documents scientifiques de niveau recherche, publiés ou non, émanant des établissements d'enseignement et de recherche français ou étrangers, des laboratoires publics ou privés. 


\title{
A rapid mechanism to remobilize and homogenize highly crystalline magma bodies
}

\author{
Alain Burgisser \\ burgisse@cnrs-orleans.fr \\ Institut des Sciences de la Terre d’Orléans, \\ CNRS/INSU, Université d’Orléans, Université François Rabelais - Tours \\ 1A rue de la Férolerie \\ 45071 Orléans cedex 2 (France)
}

George W. Bergantz

bergantz@u.washington.edu

Dept. of Earth and Space Sciences, University of Washington, Box 351310, Seattle, WA 98195-1310 USA

Main text: 1695 words

Abstract: 287 words

25 references

3 figures, 2 tables

Method summary: 300 words

Methods: 1370 words

Supplementary Information 


\begin{abstract}
The largest products of magmatic activity on Earth, the great bodies of granite and their corresponding large eruptions, have a dual nature: homogeneity at the large scale and spatial and temporal heterogeneity at the small scale ${ }^{1-4}$. This duality calls for a mechanism that 1) removes selectively the large-scale heterogeneities associated with the incremental assembly ${ }^{4}$ of these magmatic systems and 2) occurs rapidly despite crystal-rich, viscous conditions seemingly resistant to mixing ${ }^{2,5}$. Here we show that a simple dynamic template can unify a wide range of apparently contradictory observations from both large plutonic bodies and volcanic systems by a mechanism of rapid remobilization (“unzipping”) of highly viscous crystal-rich mushes. We demonstrate that this remobilization can lead to rapid overturn and produce the observed juxtaposition of magmatic materials with very disparate ages and complex chemical zoning. What is novel about our model is the recognition that the process has two stages. Initially a stiff mushy magma is reheated from below producing a reduction in crystallinity that leads to the growth of a subjacent buoyant mobile layer. When the thickening mobile layer becomes sufficiently buoyant, it penetrates the overlying viscous mushy magma. This second stage rapidly exports homogenized material from the lower mobile layer to the top of the system, and leads to partial overturn within the viscous mush itself as an additional mechanism of mixing. Model outputs illustrate the ability of unzipping to rapidly produce large amounts of mobile magma available for eruption. The agreement between calculated and observed unzipping rates for historical eruptions at Pinatubo and at Montserrat demonstrates both the general applicability of the
\end{abstract}




\section{model. This mechanism furthers our understanding of the bifurcation between crust building by formation of periodically homogenized plutons and ignimbrites formation by large eruptions.}

There is general agreement that magmatic systems in all tectonic settings are open to input of heat and mass, and are incrementally assembled ${ }^{4}$. This is manifested in complex crystal zoning patterns, age diagnostics, and volatile degassing budgets ${ }^{2-3,6-7}$, which are all evidence that the magmatic systems experienced periods of rejuvenation by chemical and thermal fluctuations. Yet despite diverse inputs, many of the largest magma bodies, frozen as large granite plutons, and their erupted products, have a uniform bulk composition at meso-to-macro scales ${ }^{1}$ although adjacent crystals have different histories $^{2,6}$. They also rarely preserve a record of the assembly process, despite the evidence for their additive nature and the entrainment of older magmatic materials ${ }^{4}$. Hence some process must be capable of efficiently removing the large-scale heterogeneities associated with assembly, and creating an environment of common intensive variables despite the viscous nature of these crystal-rich systems. Complicating any simple mechanical model that accounts for both incremental assembly and homogenization is the recognition that the geological and geophysical evidence requires that large magmatic systems persist as long-lived mushes, seemingly resistant to regular homogenization $^{6,8-9}$. And while gas sparging ${ }^{10}$ and self-mixing ${ }^{11}$ have been proposed as mechanisms of rejuvenation or mixing, neither is fully consistent with the observations that magmatic systems may not be subject to regular, substantial volatile through-put and 
that they spend long periods as rheologically stiff mushes inhibiting simple convection ${ }^{12}$.

Based on petrologic evidence, Mahood ${ }^{13}$ offered one solution by proposing a process of "defrosting", where material that is mechanically locked in the solidified margins of a magma body could be liberated by melting, and then back-mixed with a more fluid core. While theoretical modeling ${ }^{14}$ of such melting has been carried out, recent advances in the study of the rheology of crystal-rich magmas drive us to reconsider some aspects of this modeling (Supplementary Methods). Briefly, the two main controls of bulk viscosity, melt water content and crystal content, have opposite effects that closely compensate each other ${ }^{15}$. For example, the viscosity of magma with rhyolitic melt remains remarkably stable around $10^{4} \mathrm{~Pa}$ s over most of its in-situ crystallization, until a critical crystal concentration above which it significantly increases to reach the mush state. We reassess the notion of a "defrosting front” by casting it as a remobilization front moving into a mushy core, and illustrate that it is a process that can act to rapidly rejuvenate magma mushes, and mix magmatic materials of diverse ages and character into a near uniform state.

Our model considers the fate of a magma reservoir filled with a highly crystalline mush that is subjected to reheating from below by a fresh magma intrusion. The melting of the mush by the new intrusion causes the dismantlement of the crystal framework, which frees the mush little by little to form a mobile, more melt-rich and less dense layer (Fig. 1). If the melting continues undisturbed, the pre-existing mush becomes entirely remobilized as the mobile layer fills the entire chamber. We call this process, which corresponds to the classic approach ${ }^{14}$, stable front remobilization. A novel consequence of the stair-step behavior of the mush viscosity is that the hot, mobile layer is buoyant 
with respect to the colder mush. The thickening mobile layer is thus more and more prone to Rayleigh-Taylor instabilities that might penetrate the overlying mush. We call this process of penetrative overturn "unzipping" (short for "rapid remobilization by unstable front").

Figure 1 shows the evolution of the thickness of the mobile layer as a function of time when all model parameters are set to typical values for a mid-crustal reservoir (Table 1). Shortly after the emplacement of the basal, hot intrusion, the growth of the mobile layer is purely conductive. After 1.8 days, the mobile layer starts convecting to finally reach the full chamber thickness after 95 yrs, very close to the 101 yrs given by previous mode ${ }^{14}$. However, if the possibility for Rayleigh-Taylor instabilities at the interface is considered, they will start to grow faster than the mobile layer after only 68 days, when the layer is $9 \mathrm{~m}$ thick. At this point the buoyant mobile layer forms a ascending plume that penetrates the mush and reaches the chamber roof 75 days later, causing partial overturn of the remaining mush and leaving the chamber in a remobilized state. During that penetration time, the interface between mush and mobile layer would have steadily moved about $8 \mathrm{~m}$.

Fixing all parameters to their default value (Table 1) except the mush viscosity yields results shown as dashed lines on Fig. 2. Under those conditions, unzipping takes between a couple of months and a couple of decades to start and it is always shorter than stable front remobilization. We varied the other nine parameters within the range of values expected for mid-crustal magma bodies (Table 1). Onset of convection within the mobile layer is mostly controlled by the intrusion temperature and the layer viscosity, and it happens between a few days and several months (Fig. 2). Stable front remobilization is 
most affected by the intrusion temperature, mush thickness, and mush viscosity. In agreement with previous findings ${ }^{14}$, it occurs after a century to more than 10,000 years. The strongest controls of the unzipping onset time are mush viscosity, mobile layer viscosity, and intrusion temperature, owing to their wide natural variation. The other parameters exert only a minor control on unzipping, causing the onset time to vary within a factor $<1.9$ of the standard value (Supplementary Discussion). We conclude that all but the stiffest mid-crustal reservoirs are subjected to fast remobilization by unzipping within a time frame as fast as a few months, but always inferior to a few centuries. These durations are much shorter than those related to other mechanisms ${ }^{14,16,17}$ and are only comparable to the conductive remobilization of accumulated intrusions quenched to glass $^{18}$.

The thicknesses of intrusions needed for unzipping lie between 0.2 and $83 \mathrm{~m}$ (Supplementary Discussion), which is consistent with sills observed at the roots of plutons $^{19}$. Using unzipping times, these thicknesses correspond to magma supply rates of $2.110^{-3}-1.2510^{-1} \mathrm{~km}^{3} / \mathrm{yr}$, which is in agreement with the $1.210^{-2}-610^{-2} \mathrm{~km}^{3} / \mathrm{yr}$ estimated for the flare-up of major ignimbrite province ${ }^{20}$. This is in stark contrast with models ignoring the buoyancy of the mobile layer ${ }^{12,14}$, which require intrusion thicknesses on the order of that of the mush. Only a very small amount of basalt cooling by 100 degrees or so is sufficient to create the modest melting of the thin mobile layer at the base of the mush because our model involves only partial mush melting (typically 20 vol\%, Table 1). In the typical case (Fig. 1), a 3-m basalt sill would be reaching $60 \%$ crystallinity in 70 days $^{14}$, but unzipping takes only 68 days to occur. Any larger intrusion has a thermal history decoupled from that of the mush. The small amount of intrusive 
material needed and the rapidity of the process leads us to consider that unzipping is an easily-triggered mechanism yielding large volumes of eruptible magmas. Unzipping is likely to repeat itself throughout the life of the mush, until its eruption or thermal death, because cooling magma bodies spend most of their lives as mushes ${ }^{9}$. Only a few successive overturns are enough to homogenize the magma body ${ }^{9}$. This leads us to view unzipping as a likely phenomenon allowing for the incremental growth of plutons and their periodic homogenization ${ }^{4,6}$.

We tested our model against three eruptions involving the remobilization of stagnant reservoirs. The 1991 Pinatubo eruption, $\sim 5 \mathrm{~km}^{3}$ Dense Rock Equivalent (DRE) ${ }^{21}$, the current eruption of Soufrière Hills, Montserrat, $>0.44 \mathrm{~km}^{3} \mathrm{DRE}^{22}$, and the 28 -Myr-old Fish Canyon ignimbrite, $5000 \mathrm{~km}^{3} \mathrm{DRE}^{23}$, involve reservoirs of widely different scales. We considered the mush viscosity as a free parameter, but constrained the other ones by petrologic studies (Table 2). This choice takes in account the uncertainty induced by the current lack of comprehensive framework to quantify mush rheology, without reducing the generality of our model (Supplementary Discussion). As a result, we cast our model predictions as the ratio between mush and mobile layer viscosities to the unzipping onset time (Fig. 3). The observed timescale between the arrival of fresh magma under the stagnant reservoir and the eruption gives an estimation of the unzipping timescale. The observed viscosity ratio is independently estimated using the full range of cold and reheated mush crystallinities and three different rheology models (Supplementary Discussion). There are no field data for the Fish Canyon ignimbrite, as the timing of the eruption and the crystallinity of the mush are unknown.

In the case of Pinatubo, the agreement between prediction and observations is 
reasonable, the predictions of unzipping time spanning a potential two orders of magnitude. In the case of Montserrat, the field-derived time estimates mostly overlap the ones predicted by our model. If some confidence is given to our model, the fact that the overlap is restricted to the longest timescales would imply that the mush beneath Soufrière Hills was remobilized significantly before eruption, although not as early as the seismic crisis in $1966-67^{22}$. Stable front remobilization at both volcanoes would require as much time as there was between eruptions, which would leave unreasonably short time for chamber replenishment and mush formation. The Fish Canyon, one of the largest ignimbrite on Earth ${ }^{23}$, could have been remobilized in less than a couple of centuries. This duration, much smaller than the $100-200$ ka needed by gas sparging ${ }^{16}$, is only slightly longer than that of the much smaller magmatic system at Montserrat, which reflects that magma body size is not the main control of unzipping.

Although we assume that eruption occurs after mush remobilization, the case of Montserrat suggests that remobilization does not necessarily trigger eruption. Even if it is an efficient mechanism to generate large quantities of mobile, crystal-rich magma available for eruption, unzipping is a necessary but not sufficient condition for eruption. Our findings imply that the pre-eruptive partition between mobile and stiff magma can rapidly change during periods of volcanic unrest regardless of reservoir size and that an initially largely stagnant reservoir does not guarantee a small-scale eruption. As a result, mostly solidified magma bodies are at a crossroad between crust building by formation of periodically homogenized plutons and ignimbrites formation by large eruptions. 


\section{Methods summary}

The mush is assumed to be initially motionless and isothermal ${ }^{9}$. The intrusion is assumed to pond at the base of the mush and to interact with it by heat transfer only. Such under-accretion stems from defining a mush as a crystal-rich magma that does not react in a brittle fashion to the deformation rates of active magmatic processes. This leaves nearly solidified magma bodies ( $>80$ vol.\% crystals) out of our analysis because they are subject to brittle penetration and over-accretion. We do not need to take in account the thermal history of the intrusion because remobilizing a semi-rigid magma body can easily be triggered by a modest amount of fresh magma ponding beneath it (Supplementary Discussion).

At the beginning of the reheating, a layer forms by conductively melting the overlaying mush until it reaches a critical thickness at which convection starts within the now mobile later. To first-order, this remobilization can be adequately described as a homogeneous fluid with stair-step rheology (Supplementary Figures). The mobile layer then grows at a faster rate such that the heat transferred through the convecting layer balances that needed to melt the overlaying mush. We solved this classical moving boundary problem ${ }^{14}$ analytically to express the layer growth rate, $\dot{d}$, as a function of time. Under the combined effects of buoyancy and interface perturbations due to convection $^{24}$, the thickening mobile layer is prone to Rayleigh-Taylor instabilities. We formulated the evolution of an instability of amplitude $w$ starting atop of the convecting layer. Overturn starts when the growth rate of the large-scale instabilities, $\dot{w}$, is faster than that of the stable front ${ }^{24}, \dot{d}$. The partial overturn not only exports homogenized 
material from the mobile layer to the top of the system but also causes enough mixing within the mush to bring together crystals that were far apart ${ }^{25}$.

\section{References:}

1. Bachmann, O., \& Bergantz, G.W. Deciphering magma chamber dynamics from styles of compositional zoning in large silicic ash flow sheets. Reviews Mineral. Geochem. 69, 651674 (2008).

2. Charlier, B.L.A., Bachmann, O., Davidson, J.P., Dungan, M.A., \& Morgan, D.J. The upper crustal evolution of a large silicic magma body: Evidence from crystal-scale Rb-Sr Isotopic heterogeneities in the Fish Canyon Magmatic System, Colorado. J. Petrology 48, 1875-1894 (2007).

3. Davidson, J.P., Hora, J.M., Garrison, J.M., \& Dungan, M.A. Crustal forensics in arc magmas. J. Volcanol. Geotherm. Res. 140, 157-170 (2005).

4. Miller, C.F. et al Growth of plutons by incremental emplacement of sheets in crystal-rich host: Evidence from Miocene intrusions of the Colorado river region, Nevada, USA. Tectonophysics (in press).

5. Boyce, J.W., \& Hervig, R.L Magmatic degassing histories from apatite volatile stratigraphy. Geology 36, 63-66 (2008).

6. Miller, J.S., Matzel, J.E.P., Miller, C.F., Burgess, S.D., \& Miller, R.B. Zircon growth and recycling during the assembly of large, composite arc plutons. J. Volcanol. Geotherm. Res. 167, 282-299 (2007).

7. Wallace, P.J. Volatiles in subduction zone magmas: concentrations and fluxes based on melt inclusion and volcanic gas data. J. Volcanol. Geotherm. Res. 141, 217-240 (2005).

8. Hildreth, W. Volcanological perspectives on Long Valley, Mammoth Mountain, and Mono 
Craters: several contiguous but discrete systems. J. Volcanol. Geotherm. Res. 136, 169-198 (2004).

9. Huber, C., Bachmann, O., \& Manga, M. Homogenization processes in silicic magma chambers by stirring and mushification (latent heat buffering). Earth Planet. Sci. Lett. 283, 38-47 (2009).

10. Bachmann, O., \& Bergantz, G.W. Gas percolation in upper-crustal magma bodies as a mechanism for upward heat advection and rejuvenation of near-solidus magma bodies. $J$. Volcanol. Geotherm. Res. 149, 85-102 (2006).

11. Couch, S., Sparks, R.S.J., \& Caroll, M.R. Mineral disequilibrium in lavas explained by convective self-mixing in open magma chambers. Nature 411, 1037-1039 (2001).

12. Huber, C., Bachmann, O., \& Dufek, J. The limitations of melting on the reactivation of silicic mushes. J. Volcanol. Geotherm. Res. 195, 97-105 (2010).

13. Mahood, G.A. Second reply to comment of R.S.J. Sparks, H.E. Huppert and C.J.N. Wilson on "Evidence for long residence times of rhyolitic magma in the Long Valley magmatic system: the isotopic record in the precaldera lavas of Glass Mountain". Earth Planet. Sci. Lett. 99, 395-399 (1990).

14. Huppert, H.E., \& Sparks, R.S.J. The generation of granitic magmas by intrusion of basalt into continental crust. J. Petrology 29, 599-624 (1988).

15. Scaillet, B., Whittington, A., Martel, C., Pichavant, M., \& Holtz, F. Phase equilibrium constraints on the viscosity of silicic magma II: implications for mafic-silicic mixing processes. Trans. Roy. Soc. Edinburgh: Earth Sci. 91, 61-72 (2000).

16. Bachmann, O., \& Bergantz, G.W. Rejuvenation of the Fish Canyon magma body: A window into the evolution of large-volume silicic magma systems. Geology 31, 789-792 (2003).

17. Annen, C., \& Sparks, R.S.J. Effects of repetitive emplacement of basaltic intrusions on 
thermal evolution and melt generation in the crust. Earth Planet. Sci. Lett. 203, 937-955 (2002).

18. Michaut, C., \& Jaupart, C. Ultra-rapid formation of large volumes of evolved magma. Earth Planet. Sci. Lett. 250, 38-52 (2006).

19. Wiebe, R.A., \& Collins, W.J. Depositional features and stratigraphic sections in granitic plutons: implications for the emplacement and crystallization of granitic magma. J. Struct. Geol. 20, 1273-1289 (1998).

20. de Silva, S., \& Gosnold, W.D. Episodic construction of batholiths: Insights from the spatiotemporal development of an ignimbrite flare-up. J. Volcanol. Geotherm. Res. 167, 320335 (2007).

21. Self, S., Zhao, J.-X., Holasek, R.E., Torres, R.C., \& King, A.J. in Fire and Mud; Eruptions and Lahars of Mount Pinatubo, Philippines (eds C.G. Newhall \& R.S. Punongbayan) 10891115 (Univ. Washington Press, 1996).

22. Devine, J.D., Rutherford, M.J., Norton, G.E., \& Young, S.R. Magma storage region processes inferred from geochemistry of Fe-Ti oxides in andesitic magma, Soufrière Hills volcano, Montserrat, W.I.. J. Petrology 44, 1375-1400 (2003).

23. Bachmann, O., Dungan, M.A., \& Lipman, P.W. The Fish Canyon magma body, San Juan volcanic field, Colorado: Rejuvenation and eruption of an upper-crustal batholith. $J$. Petrology 43, 1469-1503 (2002).

24. Ke, Y., \& Solomatov, V.S. Plume formation in strongly temperature-dependent viscosity fluids over a very hot surface. Physics Fluids 16, 1059-1063 (2004).

25. Ruprecht, P., Bergantz, G.W., \& Dufek, J. Modeling of gas-driven magmatic overturn: Tracking of phenocryst dispersal and gathering during magma mixing. Geochem. Geophys. Geosyst. 9, Q07017, doi:10.1029/2008GC002022 (2008). 
Supplementary Information is linked to the online version of the paper at www.nature.com/nature.

Acknowledgements We thank three anonymous reviewers for thorough and constructive reviews. Work partially funded by the ERC grant 202844 under the European FP7.

Author contributions A.B. and G.W.B. participated to the theoretical construction of the model. A.B. realized the numerical implementation and produced the first draft of the paper which both authors then discussed.

Author Information The authors declare no competing financial interests. Correspondence and request for materials should be addressed to A.B. (burgisse@cnrs-orleans.fr) 


\section{Figure Caption}
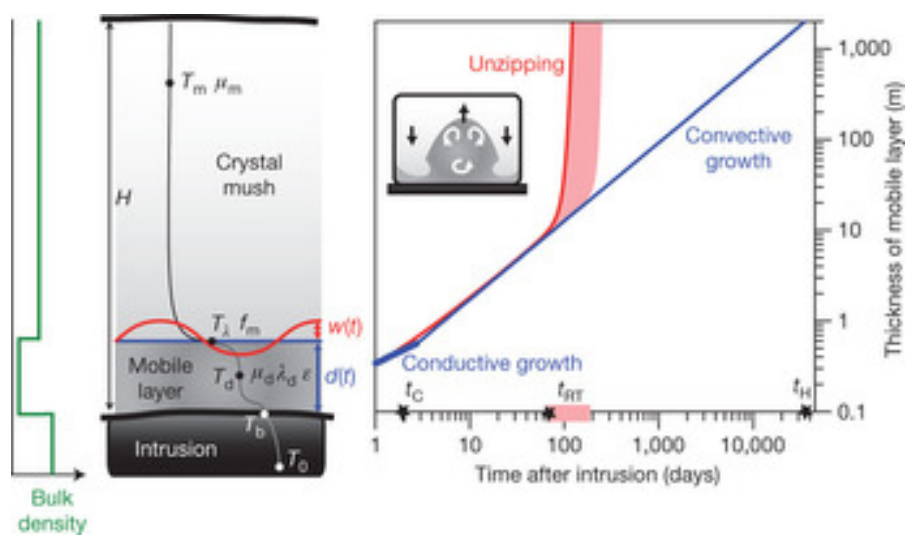

Figure 1: Schematic representation of a stagnant mid-crustal reservoir being reheated from below by an intrusion. The mush reheats in two stages by creating a convecting mobile layer that grows steadily before becoming unstable and eventually overturning the remaining mush (inset), a process we call unzipping. The process is driven by buoyancy, as illustrated by the schematic density profile on the left. Our model describes the temporal evolution of the mobile layer thickness, $d$, and the interface instability amplitude, $w$, as a function of ten free parameters (Table 1). On the right is a model output for a typical mid-crustal reservoir. The horizontal axis indicates the time at which the layer starts convecting, $t_{c}$, the time at which Rayleigh-Taylor instabilities grow faster than the mobile layer, $t_{R T}$, and the time at which the mobile layer would fill the chamber, $t_{H}$, in the absence of Rayleigh-Taylor instability. The time interval caused by the uncertainty on mush rheology is indicated by pink areas, and the minimum intrusion thickness for unzipping to occur is $1.9 \pm 0.8 \mathrm{~m}$ 
(Supplementary Discussion).

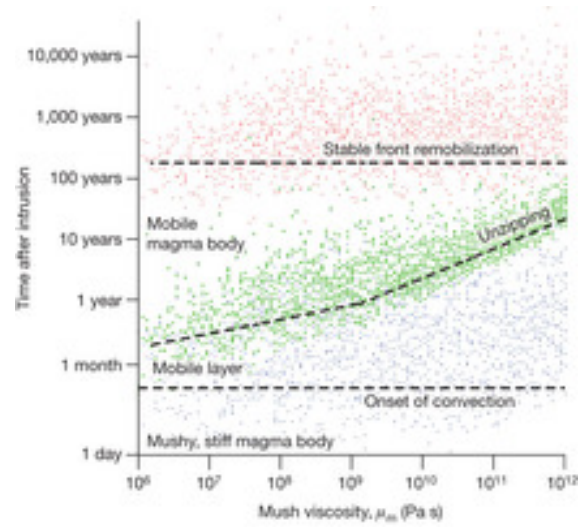

Figure 2: Time for mush melting from a steady source of heat as a function of mush viscosity. The dashed line corresponds to a typical system (Table 1), with the first line marking the onset of convection within the mobile layer, the second marking the onset time of unzipping, and the last line indicating the time taken by stable front remobilization to reach the reservoir roof. Rejuvenation happens either by unzipping or stable front remobilization, whichever occurs first. Colored dots (blue: $t_{c}$, green: $t_{R T}$, red: $t_{\mathrm{H}}, 10^{5}$ Monte Carlo runs, only 1 out of 5 shown) illustrate the variations of these three time scales as a function of the nine free parameters listed in Table 1. The kink on the unzipping curve at a mush viscosity of $10^{9.1} \mathrm{~Pa}$ s is caused by limiting the instability wavelength at the reservoir height so as to avoid unrealistically large instabilities (Supplementary Methods). 




Figure 3: Observed and predicted timescales for mush remobilization by unzipping for three natural cases. The solid-line polygons are unzipping predictions using the input parameters listed in Table 2. The colored areas cover the ranges of observed timescale between the arrival of fresh magma under the stagnant reservoir and the eruption (vertical axis), and the ratio between the viscosities of cold and reheated mush (horizontal axis, Table 2). Thick arrows and dotted frames delimit likely estimates and fading gradients indicate more speculative maximum estimates. Black and blue stars are previous eruptions at Montserrat and Pinatubo, respectively. The dashed frames are stable front remobilization times, and they closely match earlier work ${ }^{14}$. 
Table 1: Model parameters and their range for mid-crustal reservoirs.

\begin{tabular}{|c|c|c|c|}
\hline Quantities and units & Minimum & Maximum & Typical \\
\hline \multicolumn{4}{|l|}{ Free parameters: } \\
\hline$\varepsilon=$ melt volume fraction in mobile layer & 0.5 & 0.8 & 0.6 \\
\hline $\begin{array}{c}f_{m}=\text { volume fraction of melting during } \\
\text { mush reheating }\end{array}$ & 0.1 & 0.4 & 0.2 \\
\hline$T_{0}=$ temperature of the intrusion $\left({ }^{\circ} \mathrm{C}\right)$ & 870 & 1200 & 1100 \\
\hline$T_{m}=$ initial temperature of mush $\left({ }^{\circ} \mathrm{C}\right)$ & 700 & 825 & 750 \\
\hline$T_{\lambda}=$ temperature at mush $/$ mobile transition $\left({ }^{\circ} \mathrm{C}\right)$ & 730 & 850 & 800 \\
\hline$\lambda_{d}=$ viscosity ratio within the mobile layer & 1 & 10 & 5 \\
\hline$\mu_{d}=$ mobile layer average viscosity (Pa s) & $10^{3}$ & $10^{7}$ & $10^{4}$ \\
\hline$\mu_{m}=$ Newtonian mush viscosity (Pa s) & $10^{6}$ & $10^{12}$ & $10^{9}$ \\
\hline$H=$ total height of the reservoir (m) & 500 & 5000 & 2000 \\
\hline$w_{0}=$ initial perturbation of mush interface $(\mathrm{m})$ & 0.01 & 1 & 0.1 \\
\hline \multicolumn{4}{|l|}{ Calculated parameters: } \\
\hline$T_{b}=$ temperature at base, average of $T_{0} \& T_{m}\left({ }^{\circ} \mathrm{C}\right)$ & 785 & 1013 & 925 \\
\hline$T_{d}=$ mid-temperature of mobile layer $\left({ }^{\circ} \mathrm{C}\right)$ & 758 & 947 & 874 \\
\hline$\lambda_{m}=$ viscosity ratio between mobile layer $\&$ mush & $10^{-8}$ & $10^{-0.6}$ & $10^{-5}$ \\
\hline Mush crystallinity $\left(1-\varepsilon+f_{m}\right)$ & $50 \%$ & $80 \%$ & $60 \%$ \\
\hline $\begin{array}{l}\text { Model output: } \\
\qquad \begin{array}{l}d(t)=\text { thickness of the mobile layer }(\mathrm{m}) \\
w(t)=\text { amplitude of instabilities }(\mathrm{m}) \\
t_{c}=\text { onset time of convection in mobile layer }(\mathrm{s}) \\
t_{H}=\text { time for the mobile layer to reach chamber roc } \\
t_{R T}=\text { onset time of unzipping }(\mathrm{s})\end{array}\end{array}$ & & & \\
\hline
\end{tabular}

See Methods for detailed model and Fig. 1 for illustration. 
Table 2: Natural cases of remobilized magma reservoirs and their parameter range.

\begin{tabular}{|c|c|c|c|}
\hline Quantities $^{\mathrm{a}}$ & Montserrat & Pinatubo & Fish Canyon \\
\hline \multicolumn{4}{|l|}{ Model input } \\
\hline$\varepsilon^{\mathrm{b}}$ & $0.5-0.55(0.53)$ & $0.85-0.74(0.8)$ & $0.55-0.6(0.55)$ \\
\hline$f_{m}$ & 0.15 & 0.27 & $0.2-0.4$ \\
\hline$T_{0}\left({ }^{\circ} \mathrm{C}\right)$ & $930^{c}$ & 1200 & 875 \\
\hline$T_{m}\left({ }^{\circ} \mathrm{C}\right)$ & 825 & 750 & 715 \\
\hline$T_{d}\left({ }^{\circ} \mathrm{C}\right)$ & 855 & 800 & 760 \\
\hline$\lambda_{d} \mathrm{~d}$ & 2.7 & 1.8 & 2.05 \\
\hline$\mu_{d}(\mathrm{~Pa} \mathrm{~s})^{\mathrm{e}}$ & $10^{5.47}-10^{6.6}$ & $10^{4.86}-10^{5.45}$ & $10^{5.91}-10^{6.95}$ \\
\hline$H(\mathrm{~m})$ & $1500-3500$ & 4500 & 3000 \\
\hline$w_{0}(\mathrm{~m})$ & 0.1 & 0.1 & 0.1 \\
\hline \multicolumn{4}{|l|}{ Calculated } \\
\hline$T_{\lambda}\left({ }^{\circ} \mathrm{C}\right)$ & 828.4 & 817.3 & 734.6 \\
\hline \multicolumn{4}{|c|}{ Independent estimates } \\
\hline $\begin{array}{c}t_{R T}(\text { days })^{\mathrm{f}} \\
\lambda_{m}{ }^{-1 \mathrm{e}, \mathrm{g}}\end{array}$ & $\begin{array}{c}(10500) 1400-30 \\
\left(10^{4.9}\right) 10^{3.64}-10^{1.44}\end{array}$ & $\begin{array}{c}(330) 75-60 \\
\left(10^{2.1}\right) 10^{1.63}-10^{0.67}\end{array}$ & - \\
\hline
\end{tabular}

${ }^{\text {a }}$ Symbols defined in Table 1. References from which values are taken are given in Supplementary Tables.

${ }^{\mathrm{b}}$ Ranges were used to calculate $\lambda_{m}{ }^{-1}$ and average values in parenthesis were used as input in the unzipping model.

${ }^{\mathrm{c}}$ Value lowered from the original $1050{ }^{\circ} \mathrm{C}$ so that $T_{\lambda}>T_{m}$.

${ }^{\mathrm{d}}$ Average value of three rheological models (Supplementary Discussion).

${ }^{\mathrm{e}}$ Ranges given by three rheological models (Supplementary Discussion). For $\mu_{d}$, the melt viscosity and/or water content given by the literature was used.

${ }^{g}$ Values in parenthesis are extremes that delimit the outer edges of the natural domains (Fig. 3). For $\lambda_{m}{ }^{-1}$, it was done by adding 5 vol\% crystals to the mush. 


\section{Methods}

At the beginning of the reheating, the mobile layer melts conductively and the temperature at the base of the layer, $T_{b}$, is the average of intrusion temperature, $T_{0}$, and mush temperature, $T_{m}$ (see Supplementary Figures for a detailed geometry and Supplementary Tables for a full symbol list). In a standard procedure for such moving boundary problems ${ }^{14}$, we first treat the general case of the growth of a convecting mobile layer before applying the result to conductive growth. The Rayleigh number in the mobile layer is defined by the properties at the average mid-layer temperature, $T_{d}$ :

$$
R a=\frac{\Delta \rho g d^{3}}{\kappa \mu_{d}}
$$

where $d$ is the layer thickness, $g$ is the acceleration of gravity, $\kappa$ is the thermal diffusivity, $\mu_{d}$ is the layer viscosity, and $\Delta \rho=\varepsilon \alpha \rho_{0}\left(T_{b}-T_{\lambda}\right)$ is the density contrast between the hottest and the coldest parts of the layer ( $\varepsilon$ is the melt volume fraction, $\alpha$ is the thermal expansion coefficient, and $\rho_{0}$ is the reference density). The mid-layer temperature can be determined given the expected viscosity variation across the mobile layer, $\lambda_{d}$, expressed as the ratio of the highest and lowest viscosity values ${ }^{26}$ :

$$
T_{d}=T_{\lambda}+\frac{T_{b}-T_{\lambda}}{1+\lambda_{d}^{-1 / 6}}
$$

In our case it will be close to half the temperature difference between top and base of the layer. The mobile layer is growing with time by slowly melting the mush (i.e. bringing the mush from $T_{m}$ to the temperature at which the magma becomes mobile, $T_{\lambda}$ ): 


$$
\dot{d}=\frac{F}{\rho_{0}\left(c_{p}\left(T_{\lambda}-T_{m}\right)+f_{m} L_{m}\right)}
$$

where $c_{p}$ is the heat capacity of the mush, $f_{m}$ is the weight fraction of mush that melts, $L_{m}$ is the mush latent heat, and $F$ is the heat flux. By definition, the Nusselt number in the mobile layer once convection takes place is:

$$
N u=\frac{F d}{k\left(T_{d}-T_{\lambda}\right)}
$$

where $k$ is the thermal conductivity. Within the layer, the influence of convection on heat transfer can be assessed by relating $N u$ to $R a$ :

$$
N u=a R a^{b}
$$

The coefficients $a$ and $b$ have been determined either empirically ${ }^{26,27}$ or theoretically ${ }^{28}$ (Supplementary Tables). Coefficients proposed from experimental work on convection of variable viscosity fluids yield quasi identical results. Scale analysis, on the other hand, suggests that a regime change occurs in the middle of the parameter range relevant to magmatic convection, thus framing the experimental laws but creating a discontinuity cumbersome to handle for the simple model we develop herein. We thus used the experimentally-based values given by Manga and Weeraratne ${ }^{27}$.

The heat flux can be replaced in Equ. (3) by its expression using Equs. (4) and (5):

$$
\dot{d}=A d^{3 b-1} \text { with } A=\frac{a \kappa c_{p}\left(T_{d}-T_{\lambda}\right)}{c_{p}\left(T_{\lambda}-T_{m}\right)+f_{m} L_{m}}\left[\frac{\Delta \rho g}{\kappa \mu_{d}}\right]^{b}
$$

Here, the remobilization process (i.e. bringing the mush from $T_{m}$ to the mobile layer temperature $T_{d}$ ) has been assumed to have negligible effects on the values of $c_{p}, k$, and $\kappa$, 
thus allowing us to use single values for the mush and the mobile layer. Taking in account that $b$ is comprised between 1/5 and 1/3 (Supplementary Tables) and that $d(t=0)=0$, integration of Equ. (6) gives:

$$
t=\frac{d^{2-3 b}}{A(2-3 b)}
$$

The critical Rayleigh number, $R a_{c}=1708$, can be used to obtain the critical thickness of the mobile layer, $d_{c}$ :

$$
d_{c}=\left(\frac{\kappa R a_{c} \mu_{d}}{\Delta \rho g}\right)^{1 / 3}
$$

The time at which convection starts, $t_{c}$, can be obtained by setting $a=1$ and $b=0$ so as to have a Nusselt number of one, and evaluating Equ. (7) at $d=d_{c}$. The mush becomes entirely remobilized when the mobile layer fills the entire chamber, which occurs at the time, $t_{H}$, given by evaluating Equ. (7) at $d=H$.

The growth rate of the mobile layer can now be expressed as:

$$
\dot{d}=A^{\frac{1}{2-3 b}}[(2-3 b) t] \frac{1}{2-3 b}-1
$$

Assuming that under-plating occurs over an area of $\mathrm{H}^{2}$ (i.e. a cubic mush reservoir with an intrusion spreading beneath its entire floor), the total thermal energy, $T_{J}$, needed for remobilization is given by:

$$
T_{J}=H^{2} \int_{0}^{t} F(\phi) d \phi
$$

where $\phi$ is a integration variable for time. Using Equs. (3) and (9) to express $F$ and 
integrating yields:

$$
T_{J}=H^{2} \rho_{0} c_{p}\left(T_{\lambda}-T_{m}\right)[(2-3 b) A t]^{\frac{1}{2-3 b}}
$$

Dividing $T_{J}$ by $H^{2} \rho_{b}\left[c_{p(b)}\left(\frac{T_{0}-T_{m}}{2}\right)+f_{b} L_{b}\right]$ yields the minimum total thickness of the basalt layer, $H_{b}\left(f_{b}\right.$ is the weight fraction of basalt that crystallizes when cooling from $T_{0}$ to $T_{b}, \rho_{b}$ is the basalt density, $C_{p(b)}$ is the basalt heat capacity and $L_{b}$ is the latent heat of crystallization). The maximum thickness of the basalt layer can be estimated using a simple conductive approach by which the temperature decrease at the interface between intrusion and mush is given by ${ }^{29} \operatorname{erfc}\left(H_{b} / \sqrt{\kappa_{b} t}\right)\left(T_{0}-T_{m}\right) / 2\left(\kappa_{b}\right.$ is the basalt thermal diffusivity). Our approach assumes that this difference, say $0.5^{\circ} \mathrm{C}$, remains small over $t_{R T}$, and the above equation can be used to calculate $H_{b}$.

Unzipping starts when the growth rate of the large-scale instabilities is faster than the growth rate of the mobile layer itself. The duration from intrusion emplacement to unzipping is $t_{R T}$. Canright and Morris ${ }^{30}$ described the growth of a perturbation of amplitude $w(t)$ at the interface between two fluid layers of contrasted viscosities. They show that the perturbation growth law depends on the rheology of the fluids, either Newtonian or non-Newtonian. Below we adapt their resolution in order to obtain salient laws for $w(t)$ and estimate $t_{R T}$ by solving $\dot{d}=\dot{w}$.

\section{Newtonian rheology}

A Newtonian mush has a linear relationship between strain rate, $\dot{\gamma}$, and shear stress, $\tau:$ 


$$
\tau=\mu_{m} \dot{\gamma}
$$

The development of an instability starting after the onset of convection in the mobile layer follows ${ }^{30}$ :

$$
w(t)=w_{0} \exp \left(\frac{\Delta \rho_{m} g d}{\mu_{m}} \tilde{\sigma}\left(t-t_{c}\right)\right)
$$

where $\Delta \rho_{m}$ is the density contrast between the mush and the mobile layer, $w_{0}$ is the initial amplitude of the instability, and $\tilde{\sigma}$ is the dimensionless growth rate. The density variation in the mobile layer is a combination of the change in crystal content and the reheating of the interstitial liquid: $\Delta \rho_{m}=f_{m}\left(\rho_{c}-\rho_{0}\right)+\varepsilon \alpha \rho_{0}\left(T_{d}-T_{m}\right)$, where $\rho_{c}$ is the average density of the solid phases that melt. To reduce the degrees of freedom of the model, we fixed $\rho_{c}=2700 \mathrm{~kg} / \mathrm{m}^{3}$, which corresponds to plagioclase, a phase generally abundant in mushes. The dimensionless growth rate is given by ${ }^{30}$ :

$$
\tilde{\sigma}=\frac{\lambda_{m}(s / K-1)(C-1)+(K-\beta)(c-1)}{2 \lambda_{m}\left(C c-1+\beta K^{2}\right)+\lambda_{m}^{2}(S+\beta K)(s-K)+(S-\beta K)(s+K)}
$$

where the symbols $s=\sinh (K), c=\cosh (K), S=\sinh (\beta K)$, and $C=\cosh (\beta K), \beta=d /(H-d)$ and $K=4 \pi(H-d) / \eta$ have been used, $\lambda_{m}=\mu_{d} / \mu_{m}$ is the viscosity ratio between mobile layer and mush, and $\eta$ is the wavelength of the instability. In the parameter range of interest $\left(\beta<10^{-0.2}, 10^{-8}<\lambda_{m}<10^{-0.6}\right)$, there is always a wavelength, $\eta_{\max }$, for which the dimensionless growth rate, $\tilde{\sigma}_{\max }$, is maximum. It can be found by solving:

$$
\frac{d \tilde{\sigma}}{d K}=0
$$


Instability onset time, $t_{R T}$, can then be obtained by solving $\dot{d}=\dot{w}$ :

$$
\left[(2-3 b) A t_{R T}\right]^{\frac{1}{2-3 b}}=w_{0} \exp \left(\frac{\Delta \rho_{m} g}{\mu_{m}} d \tilde{\sigma}_{\max } t_{R T}\right) \frac{\Delta \rho_{m} g}{\mu_{m}}\left(d \tilde{\sigma}_{\max }+\dot{d} \tilde{\sigma}_{\max } t_{R T}+d \dot{\tilde{\sigma}}{ }_{\max } t_{R T}\right)
$$

\section{Non-Newtonian rheology}

The rheologic law of a non-Newtonian mush can be expressed as power law of exponent $\mathrm{M}>1$ and consistency coefficient $\mu_{m(0)}$ :

$$
\tau=\mu_{m(0)} \dot{\gamma}^{1 / M}
$$

The growth of a perturbation of amplitude $w(t)$ becomes $^{30}$ :

$$
w(t)=w_{0}\left[1-(M-1)\left(\frac{\Delta \rho_{m} g}{4 \mu_{m(0)}}\right)^{M} w_{0}^{M-1} d\left(t-t_{c}\right)\right]^{\frac{1}{1-M}}
$$

The time for the large scale instability to grow faster than the mobile layer can thus be evaluated by deriving $\dot{w}$ from Equ. (18) and replacing the right-hand-side of Equ. (16) by it:

$$
\left[(2-3 b) A t_{R T}\right] \frac{1}{2-3 b}=d\left(\frac{w\left(t_{R T}\right) \Delta \rho_{m} g}{4 \mu_{m(0)}}\right)^{M}
$$

\section{Numerical Resolution}

For the Newtonian case, the time for the onset of large-scale instabilities, $t_{R T}$, is found by fixing all parameters $\left(\Delta \rho_{m}, \mu_{d}, \mu_{m}, w_{0}\right)$ and solving successively Equs. (15) and (16) numerically. Assuming that $\dot{\tilde{\sigma}}=0$ in Equ. (16) causes errors on $t_{R T}<9 \%$, and further assumption that $\dot{d}=0$ in the right-hand side of Equ. (16) increases these errors to $<16 \%$. 
For the non-Newtonian case, $t_{R T}$ is found by fixing all parameters and solving Equ. (19) numerically (Supplementary Figures). All equations are solved using Newton-Raphson root finding algorithm. The thickness of the mobile layer at which unzipping starts, $d_{R T}$, can then be found using Equ. (7). The time, $t_{P}$, for the large-scale Rayleigh-Taylor instability to reach the roof of the reservoir can be calculated, if its amplitude is small, by solving Equ. (13) for $w\left(t_{P}\right)=H-d$ with $\tilde{\sigma}_{\max }$ evaluated at $d_{R T}$.

Estimating the strain rate and the shear stress applied to the mush during unzipping is useful to determine which rheology applies best to the unzipping process. To first order, the strain rate can be obtained by evaluating stress caused by the growth of the instability near its tip. For a Newtonian rheology, it is independent of time:

$$
\dot{\gamma}=\frac{d \dot{w}}{d w}=\frac{\Delta \rho_{m} g \tilde{\sigma} d_{R T}}{\mu_{d}}
$$

For a non-Newtonian rheology, the strain rate depends on time and is evaluated at the onset of unzipping:

$$
\dot{\gamma}=\frac{d \dot{w}}{d w}=w\left(t_{R T}\right)^{M-1} M d_{R T}\left(\frac{\Delta \rho_{m} g}{4 \mu_{m(0)}}\right)^{M}
$$

The shear stress can then be evaluated by using the rheological laws, Equs. (12) and (17), respectively. If the mush rheology is such that a yield stress exists, the mush will be set in motion when the static stress applied to the mush by the buoyancy of mobile layer reaches a certain value. This stress is a function of the roughness of the melting interface, which we relate here to the size of the initial perturbation: 
$\tau_{\text {static }}=\Delta \rho_{m} g w_{0}$

\section{References of Methods}

26. Schaeffer, N., \& Manga, M. Interaction of rising and sinking mantle plumes. Geophys. Res. Lett. 28, 455-458 (2001).

27. Manga, M. \& Weeraratne, D. Experimental study of non-Boussinesq Rayleigh-Bernard convection at high Rayleigh and Prandtl numbers. Phys. Fluids 11, 2969-2976 (1999).

28. Grossmann, S. \& Lohse, D. Thermal convection for large Prandtl numbers. Phys. Rev. Letters 86, 3316-3319 (2001).

29. Crank, J. The mathematics of diffusion. (Oxford University Press, Oxford, UK, 1975).

30. Canright, D., \& Morris, S. Buoyant instability of a viscous film over a passive fluid, J. Fluid Mech. 255, 349-372 (1993). 